\title{
REINCIDÊNCIA PENAL: UMA ANÁLISE A PARTIR DA “ECONOMIA DO CRIME” PARA SUBSIDIAR DECISÕES JUDICIAIS
}

\section{RECURRENCE CRIMINAL LAW: AN ANALYSIS FROM THE "CRIME ECONOMY" TO SUBSIDIZE JUDICIAL DECISIONS}

"A pior coisa que têm os maus costumes é serem costumes, ainda é pior que serem maus" (Padre Antônio Vieira)

\author{
Pery Francisco Assis Shikida ${ }^{1}$ \\ Carlos Alberto Gonçalves Júnior ${ }^{2}$ \\ Bárbara Françoise Cardoso ${ }^{3}$ \\ Luiz Gilberto Birck ${ }^{4}$
}

\section{RESUMO}

Este artigo analisa os determinantes da reincidência penal no Brasil por meio de um estudo empírico no Complexo de Penitenciárias de Piraquara (Paraná), a partir de dados primários obtidos via aplicação de questionários/entrevistas a réus já julgados e condenados por crimes econômicos. Nesta pesquisa, para os criminosos reincidentes, o crime compensa mais do que o trabalho lícito, com tendência para o furto, tráfico de drogas e roubo, nesta sequência. O contexto geral das variáveis analisadas permite inferir que o criminoso reincidente direciona esforços e parcela do seu tempo numa atividade ilícita visando o sucesso pecuniário de sua ação, não reincidindo caso haja expectativa de baixo retorno.

Palavras-chave: Estudo empírico. Modelo Logit. Complexo de Penitenciárias de Piraquara.

\begin{abstract}
This paper analyzes the determinants of criminal recidivism in Brazil through an empirical study at Piraquara Prison Complex (Paraná, Brazil), based on primary data obtained via questionnaires/interviews from defendants already found guilty by economic crimes. In this research, for criminals recidivist, the crime compensates more than legal work, with a tendency for theft, drug trafficking and robbery, in this order. The general context of the analyzed variables makes it possible to affirm that the criminal recidivist heads the efforts and part of his time to an illicit activity aiming the pecuniary success of the action, and do not relapse in case if there is a chance of low return.
\end{abstract}

Keywords: Empirical study. Logit model. Piraquara Prison Complex.

1 Economista, doutor em Economia Aplicada pela ESALQ/USP. Pós-doutorado pela FGV/SP. Professor Associado da Universidade Estadual do Oeste do Paraná (UNIOESTE). Bolsista de Produtividade em Pesquisa do CNPq. E-mail: peryshikida@hotmail.com

2 Economista, mestre em Desenvolvimento Regional e Agronegócio pela UNIOESTE. Professor Assistente da UNIOESTE. E-mail: carlosalbertojr@hotmail.com 3 Gestora de Agronegócio, doutoranda em Desenvolvimento Regional e Agronegócio pela UNIOESTE. Bolsista CAPES/Fundação Araucária. E-mail: barbarafcardoso@gmail.com

4 Mestre em Desenvolvimento Regional e Agronegócio, Professor Assistente da Universidade Estadual do Oeste do Paraná. Email: gilbirck23@yahoo.com.br 


\section{INTRODUÇÃO}

A reincidência penal é um fenômeno que vem preocupando economistas e a sociedade em geral por interferir na atividade econômica do país e no bem-estar e senso de segurança da sociedade. Estudos sobre a reincidência no Brasil têm mostrado que $70 \%$ dos presidiários que são libertados retornam às prisões, sendo que no Estado do Paraná esse valor chega a 30\%. Ressalta-se que, em dezembro de 2011, havia 514.582 carcerários no Brasil, sendo 33.586 no Paraná, ou seja, 6,53\% da população carcerária brasileira encontravam-seneste estado (DEPARTAMENTO PENITENCIÁRIO NACIONAL, 2011). Os motivos pelos quais este valor ainda é alto no Brasil não são totalmente esclarecidos pela teoria econômica do crime, por isso há necessidade de estudos pontuais a respeito da reincidência penal.

Alguns fatores explicativos serão analisados no decorrer deste artigo, que tem como escopo analisar os determinantes da reincidência penal no Brasil, por meio de um estudo empírico no Complexo de Penitenciárias de Piraquara (Paraná), a partir de dados primários obtidos através da aplicação de questionários/entrevistas a réus já julgados e condenados por crimes de natureza econômica. Ainda com o objetivo de estimar os determinantes da reincidência penal será analisada a correlação, em termos probabilísticos, por meio do modelo Logit, de variáveis pessoais, socioeconômicas e de interação social com uma variável dependente binária construída para capturar a reincidência penal.

Diante das dificuldades de uma pesquisa de campo nos ambientes carcerários, priorizou-se o foco deste estudo nos crimes considerados econômicos. Afora a questão jurídica - ver Brenner (2009) -, o crime pode ser classificado em dois grupos: o não lucrativo ou não econômico - homicídio, estupro, abuso de poder, tortura etc; e o lucrativo ou econômico - furto, roubo ou extorsão, usurpação, estelionato, receptação, crimes contra a administração pública, tráfico de entorpecentes (droga), entre outros (BECKER, 1968). Ressalta-se que, no Paraná, 12.731 detentos foram presos por crimes econômicos, o que representa $37,9 \%$ da população carcerária paranaense (DEPARTAMENTO PENITENCIÁRIO NACIONAL, 2011).
A abordagem teórica deste artigo, baseada na teoria da escolha racional, está circunscrita à economia do crime, que assevera que o agente criminoso, de natureza econômica, age racionalmente com base nos custos e benefícios inerentes às oportunidades legais e ilegais, advindas da escolha ocupacional de trabalho. O crime, portanto, é uma atividade econômica como qualquer outra, sendo sua prática resultado de uma ponderação entre o benefício auferido pelo ato ilícito, o risco de ser detido, de ter a pena devidamente aplicada e as alternativas de alocação do tempo. $\mathrm{Na}$ realidade, essa teoria do comportamento criminal baseia-se na suposição de escolha racional, conforme inicialmente proposto por Bentham (BENTHAM, 1843; BECKER, 1968; EIDE, 1999; COOTER e ULEN, 2010).

\section{BREVES NOTAS SOBRE A REINCIDÊNCIA PENAL E A ECONOMIA DO CRIME}

O sentido da palavra reincidência exprime o efeito ou ato de incidir novamente, de tornar a praticar um ato da mesma espécie, de recair, tratando-se, em certos casos, de uma obstinação, uma teimosia na prática de certa conduta, o mesmo que recidiva (PAULA, 2003; MACHADO, 2006).

O Código Penal brasileiro não habilita um conceito para a reincidência, somente fixa o momento em que ela se verifica. Neste caso, é indispensável a existência de dois crimes para que se configure a reincidência penal, sendo um posterior ao outro, praticados pelo mesmo agente que já tenha sido condenado em caráter definitivo pelo primeiro crime, portanto, com sentença condenatória transitada e julgada. Neste ínterim, a doutrina expõe a existência de duas formas de reincidência: a real - quando o condenado já cumpriu efetivamente sua pena; e a ficta - se for cometida nova infração após condenação por sentença para a qual não caiba mais recurso, independentemente de ter cumprido a pena. Há também a reincidência genérica que não requer que os delitos sejam da mesma natureza, e a reincidência específica que exige que os delitos sejam da mesma natureza (PAULA, 2003).

Revisitando o Artigo 63 do Código Penal do Brasil, "verifica-se a reincidência quando o agente comete novo crime, depois de transitar em julgado a sentença que, no País ou no estrangeiro, o tenha 
condenado por crime anterior" (CÓDIGO PENAL. Decreto-Lei no 2.848 , de 7 de dezembro de 1940 . Disponível em: $<$ http://www.planalto.gov.br/ccivil_03/decreto-lei/Del2848compilado.htm>. Acesso em: 21 ago. 2011).

Complementarmente, o Artigo 64 diz que para efeito de reincidência são necessárias as seguintes condições: "I - não prevalece a condenação anterior, se entre a data do cumprimento ou extinção da pena e a infração posterior tiver decorrido período de tempo superior a 5 (cinco) anos, computado o período de prova da suspensão ou do livramento condicional, se não ocorrer revogação; II - não se consideram os crimes militares próprios e políticos" (CÓDIGO PENAL).

Não é intento do estudo perscrutar o mérito dos fundamentos da reincidência enquanto objeto do sistema penal (que é composto por três ramos do direito, distintos e inter-relacionados, quais sejam: Direito Penal, Direito Processual Penal e Direito da Execução Penal) [ver Pierangelli (1980); Barreiros (2007)]. Aqui o escopo é analisar os determinantes da reincidência penal no Brasil, por meio de um estudo empírico aplicado no estado do Paraná. O norte da reincidência penal está, neste enfoque, ligado à economia do crime, que advoga que um infrator reage aos incentivos, positivos e negativos, sendo as infrações cometidas influenciadas pela alocação de recursos públicos e privados para fazer frente ao cumprimento da lei; assim, este comportamento criminoso é visto como uma atitude eminentemente racional, e não meramente emotiva, irracional ou antissocial (BALBINOTTO NETO, 2003) [ver Cerqueira e Lobão (2003), Mariano (2010), Cooter e Ulen (2010)].

Neste contexto de racionalidade é que a reincidência penal está incorporada. Isto pressupõe, $a$ fortiori, que os reincidentes numa atividade criminal de natureza econômica também agem de forma racional e impetuosa, com oportunismo diante de um ambiente propício e factível ao ilícito, sem nenhuma preocupação com a moral da atividade ou com o bem-estar social, pensando somente em obter para si ou para outrem benefícios lucrativos (BEMFICA, 1990; BRENNER, 2009; SHIKIDA, 2010).

Becker (1968) assume que uma pessoa age racionalmente com base nos custos e benefícios inerentes às oportunidades legais e ilegais da economia, tendo consciência de quão bom poderá ser o lucro advindo de uma atividade ilícita e quão ruim poderá ser a sua punição. Assim, "[...] indivíduos racionais se tornam criminosos quando os retornos do crime, financeiros ou de outro tipo, superam os retornos do trabalho em atividades legais, levando em consideração a probabilidade de detenção e condenação, assim como a severidade da punição" (FAJNZYLBER, 2000, p.1).

Embora Becker tenha dito que "[...] 'crime' is an economically important activity or 'industry', notwithstanding the almost total neglect by economists" (BECKER, 1968, p. 170), a teoria econômica do crime experimentou mais recentemente alguns avanços no estudo da criminalidade, fundamentada, principalmente, em modelagens matemáticas.

No aspecto específico da reincidência penal, a teoria de Becker (1968) - testada com escopos e metodologias diferenciadas, mas que abarcaram sob vários ângulos a criminalidade econômica [ver Eide (1999), Schaefer (2000), Araujo Jr. (2002), Brenner (2009), Shikida (2010)] - sinaliza que os criminosos reincidentes tendem a reduzir os custos associados à prática ilícita na medida em que os custos morais, o custo econômico e o custo de oportunidade diminuem, devido ao ganho de expertise (learning by doing) em suas atividades ilegais, aumentando o nível de criminalidade, pois as pessoas que já cometeram crime terão mais facilidade para elaborar e efetuar novas atividades criminosas.

Conforme Cerqueira e Lobão (2003), dois importantes aspectos são necessários para tentar explicar o comportamento criminoso: a compreensão de suas motivações individuais; e o entendimento de como este comportamento se distribui e se desloca no espaço e no tempo. Ao se propor analisar os determinantes da reincidência penal, busca-se analisar algumas variáveis pessoais, socioeconômicas e de interação social necessárias à compreensão da reincidência e de suas motivações para tentar explicar este tipo de comportamento criminoso, isto a partir de estudo empírico no Complexo de Penitenciárias de Piraquara. Os dados coletados são cross section (dados relativos a um único período de tempo), mas sua instrumentalização irá propiciar um retrato dos determinantes da reincidência penal. Diante do contexto em que o pesquisado oferece uma série de informações que serão operacionalizadas econometricamente, a pergunta que se quer responder é: quais são os fatores motivadores 
e contramotivadores da criminalidade econômica, especificamente no caso da reincidência penal para crimes de natureza econômica?

\section{METODOLOGIA DE BUSCA DE DADOS PRIMÁRIOS E METODOLOGIA ECONOMÉTRICA}

A escolha do estado do Paraná deu-se em razão da acessibilidade aos estabelecimentos do Complexo de Penitenciárias de Piraquara, que compreende as Penitenciárias Central, Estadual e Feminina de Piraquara, fato este relevante diante das dificuldades inerentes a uma pesquisa de campo correlata ao assunto criminalidade.

Utilizaram-se dois procedimentos complementares: a busca dos dados mediante pesquisa de campo, de caráter qualitativo, e seu tratamento econométrico, de caráter quantitativo.

Quanto ao primeiro procedimento, cumpre dizer que foi necessária a efetivação de uma pesquisa no interior do Complexo de Penitenciárias de Piraquara, visando à obtenção de dados primários necessários para o tratamento econométrico. A obtenção dos dados explicativos sobre a criminalidade e reincidência penal - através da aplicação de questionários/entrevistas a réus já julgados e condenados por crimes econômicos - ocorreu mediante contato direto e interativo de pesquisadores com detentos que se dispuseram a contribuir com o presente trabalho.

A autorização para esta pesquisa foi dada pelas autoridades competentes do governo do Paraná. A cronologia do trabalho de campo, mais especificamente as datas de visita nos estabelecimentos (foi gasto aproximadamente um ano), bem como o teor do questionário em si, que se baseou na fundamentação teórica da economia do crime, pelo fato de expor aspectos considerados de segurança pública, mormente no caso de reincidência penal, serão mantidos em sigilo conforme orientação do governo do Paraná.

Contudo, antes da aplicação do questionário consultou-se Becker (1999), que expõe condutas de como se comportar na coleta de dados em estabelecimentos carcerários. Houve, conforme apregoa Gil (2000), antes da aplicação final do questionário alguns pré-testes, que visavam avaliar as possíveis ambiguidades e deficiências deste instrumento de pesquisa, bem como para melhor adaptação ao contexto de um trabalho dentro do estabelecimento carcerário.

Outro item importante na aplicação dos questionários/entrevistas reside no fato da amostra pesquisada ser do tipo não probabilística, conhecida como amostragem possível ou por acessibilidade (GIL, 2000), pois ficou a critério do detento colaborar ou não. Entre as principais razões para a não colaboração está a desconfiança de que este instrumento de pesquisa possa vir a comprometer futuras ações e/ou parceiros dos respondentes, ou pela desconfiança de que as perguntas feitas sejam instrumentos do Estado para prejudicá-lo. Mesmo assim foram pesquisadas 262 pessoas, que representam cerca de $32 \%$ do universo disponível. Ademais, nesta composição de pessoas, buscou-se abarcar todos os tipos de crimes econômicos e o seus mais variados perfis. Cada entrevista durou cerca de 30 minutos, feita por uma equipe de três pesquisadores devidamente treinados para este fim.

Quanto ao tratamento econométrico dos dados, de caráter quantitativo, contempla-se a segunda fase desta análise empírica. Destarte, supõe-se que diversos subvetores influenciam na reincidência penal, como: características pessoais, de herança familiar, socioeconômicas, fatores catalisadores, religiosos, de hábitos e gostos etc., que são selecionados como variáveis explicativas da probabilidade de ser reincidente. Isto posto, a amostra obtida foi composta por $80 \%$ de indivíduos do sexo masculino, que é maior no ambiente carcerário - 94\% no Brasil e 95\% no Paraná (DEPARTAMENTO PENITENCIÁRIO NACIONAL, 2010).

A variável dependente binária (reincidência) foi construída do seguinte modo:

Reincidente $=1$, caso o indivíduo tenha reincidido no crime econômico;

Não reincidente $=0$, caso contrário.

Como variáveis explicativas da probabilidade de ser reincidente foram selecionadas várias características: dummies de gênero (masc), cor (bra), idade (por faixas etárias), escolaridade fundamental, média e superior (esc_fun, esc_med, esc_sup, respectivamente), possuir trabalho (trab), casamento (cas), uniões desfeitas (união_desf), renda suficiente (ren suf), imóvel (im), carteira assinada (cartass), escolaridade fundamental, média e superior dos pais (escp fun, escp_med, escp_sup), pais trabalhando (trabp), 
antecedentes criminosos na família (antec fam) etc. foram incluídas na análise para procurar captar a influência das características socioeconômicas, pessoais e de herança familiar. Acreditar no judiciário (jud), possuir arma (arma), parceiro no crime (uma proxy para interação social - parc_crime), conhecer anteriormente a vítima (vit_conh) são variáveis dicotômicas que controlam o efeito dos fatores catalisadores. Como variáveis que mensuram a importância da religiosidade e de hábitos e gostos têm-se acreditar em Deus (Deus), praticante de uma religião (praticante), beber (bebe), fumar (fuma), fazia uso de drogas (drog_antes) e faz uso de drogas (drog_hoje).

Para Barth (2004), em casos nos quais se busca calcular a probabilidade de ocorrência de uma determinada variável qualitativa em função de outras variáveis qualitativas, o modelo mais adequado para a estimação dos parâmetros é o Logit. Principalmente por não exigir normalidade multivariada dos regressores.

Outra opção para a estimação dos parâmetros em modelos dessa natureza é o modelo Probit. No entanto, de acordo com Hill et al. (2006), a estimação do modelo Probit é numericamente complicada por basear-se na distribuição normal, por isso, uma alternativa frequentemente usada para o modelo Probit, em situações de escolha binária, é o modelo Logit.

Utilizando-se o modelo Logit, espera-se obter a probabilidade de reincidência em crimes da seguinte equação:

Reincidência $=f$ (características pessoais, socioeconômicas, de herança familiar, fatores catalisadores, religiosos e de hábitos e gostos) $+\varepsilon$

Neste sentido, o fito desta proposta de estudo é estimar os determinantes da reincidência analisando-se a correlação, em termos probabilísticos, das variáveis mencionadas anteriormente com uma variável dependente binária construída para capturar o que caracteriza como uma pessoa reincidente no crime econômico, particularmente de pesquisados já julgados, condenados e localizados no Complexo de Penitenciárias de Piraquara.

Destarte, visando verificar como tal comportamento é determinado entre os pesquisados, supõe-se a seguinte relação:

$$
\ln \left[\frac{P}{1-P}\right]=b_{0}+b_{1} X_{1}+b_{2} X_{2}+\ldots+b_{n} X_{n}+e
$$

Em que:

$P=$ é a probabilidade de reincidência;

$(1-P)=$ é a probabilidade de não reincidência;

$X_{i}=$ são as variáveis explicativas;

$b_{i}=$ são os coeficientes a serem atribuídos a cada uma das variáveis $X_{i}$, porém, não esquecendo que a interpretação de $b_{i}$ e $P$ não é imediata devido à existência da função $\ln$.

Para o modelo utilizado, após a coleta primária das variáveis independentes, utilizou-se um método estatístico para a escolha das variáveis significativas, denominado stepwise forward. De acordo com Hosmer e Lemeshow (2000), no método stepwise forward parte-se de um modelo sem nenhuma variável explicativa e a cada passo são incluídas variáveis relevantes, até a obtenção do modelo final. Este método é utilizado em situações em que não se conhecem previamente quais as variáveis independentes mais importantes para a composição do modelo. Tais situações são comuns em assuntos em que a variável resposta é um assunto novo, como é o caso da reincidência em crimes econômicos.

\section{RESULTADOS E DISCUSSÕES}

A escolha das variáveis independentes primeiramente foi feita pela relevância teórica de cada variável, isto é, em termos teóricos, as características pessoais, socioeconômicas, de herança familiar, fatores catalisadores, religiosos e de hábitos e gostos são variáveis que podem influenciar na probabilidade de reincidência em crimes econômicos.

Posteriormente, fez-se uma seleção das variáveis por sua significância estatística, utilizando o método stepwise forward, entre todas as variáveis que inicialmente compuseram o modelo. O proposto método estatístico selecionou após o $13^{\circ}$ passo as seguintes variáveis: praticante de uma religião (praticante); sem instrução escolar (esc_sem_inst); composição familiar com pai, mãe e irmãos (comp_f_p_m_i); composição familiar sozinho (comp_soz); uso de drogas (usava_drog); tipo de crime roubo (roubo_157); tipo de crime furto (furto_155); tipo de crime tráfico de drogas (traf_drog_12); uso de arma de fogo (uso_arma_fog); possui imóvel (imóvel); alto sucesso na atividade ilícita (alto_suc_7); baixo retorno econômico (ret_econ_0); além da constante. Tais variáveis, com suas respectivas representações 
de valores e significância, estão retratadas na Tabela 1 , bem como as variáveis selecionadas pelo método stepwise forward, o teste Wald e os parâmetros estimados pelo modelo Logit.

Cumpre dizer que o teste Wald segue uma distribuição qui-quadrado, logo os valores calculados pelo teste precisam ser maiores que o valor tabelado da estatística qui-quadrado para a rejeição da hipótese nula do parâmetro. $\mathrm{O}$ valor tabelado de tal estatística, com 1 grau de liberdade e 0,1 de significância é 2,70554 (a probabilidade de inclusão da variável pelo método stepwise foi ampliada para o nível de significância de 0,15 , porém já são significativas a 0,1 , ou seja, menor que todos os calculados pelo teste Wald; por isso, todos os parâmetros, mesmo que analisados individualmente, são significativos, o que, considerando o modelo de regressão logística, leva à (equação abaixo):

Em que $P$ é a probabilidade de reincidência, e as variáveis independentes são as descritas na Tabela 1 .

Cada coeficiente é interpretado como uma estimativa do efeito que cada variável independente produz individualmente na variável dependente, mantendo as demais constantes. Neste sentido, o coeficiente de furto_155, equivalente a 4,191, significa que, mantidas as demais variáveis constantes, se o furto_155 aumenta em uma unidade, o Logit estimado aumenta, em média, cerca de 4,191 unidades.

Todavia, uma interpretação mais interessante se dá em termos das chances, que são obtidas tomando-se o antilogaritmo do coeficiente. Assim, tomando-se o antilogaritmo do mesmo coeficiente furto_155 $\left(e^{4,191}=66,08\right)$, verifica-se que um agente criminoso, por motivo de furto, tem 66 vezes mais chance de ser reincidente.

Segundo Borilli (2005), o furto é uma atividade criminal de muita ocorrência em função dos seus praticantes terem dois fatores motivadores: $1^{\circ}$ ) a esperança de que os ganhos com esta atividade ilícita superem os riscos da atividade, o que exige um relativo empenho da racionalidade para que uma determinada coisa alheia móvel possa ser subtraída e de como fazer isto de modo furtivo ou fraudulentamen- te, concebendo também uma relação entre a pessoa e o objeto a ser furtado, que transcende o tempo e o espaço. Portanto, torna-se mister ser racional no furto, primeiramente para discernir entre não precisar empregar a violência e empregá-la, o que já caracterizaria, neste último caso, no roubo.

No caso do roubo, uma pessoa presa por este motivo tem 6 vezes mais chance de ser reincidente, um número 11 vezes menor do que no caso do furto. O segundo fator motivacional que Borilli (2005) ressalta está na análise de custo e benefício feita pelo agente criminoso, pois, para o roubo a punição deverá ser maior em função do uso da violência ou grave ameaça efetivada contra a pessoa. Isto reporta ao argumento básico da abordagem da teoria econômica do crime, citado por Balbinotto Neto (2003), pelo fato dos criminosos que atuam neste campo reagirem aos incentivos, tanto negativos como positivos, e que o número de vezes de crimes cometidos é influenciado pela análise do custo e benefício, alocação de recursos para fazer frente ao cumprimento da lei e de outros meios de coibi-los.

As variáveis explicativas da probabilidade de ser reincidente que procuram captar a influência das características socioeconômicas, pessoais e de herança familiar, com significância estatística, foram: sem instrução escolar (esc_sem_inst), uma pessoa da atividade criminal com esta característica tem 8,7 vezes mais chance de ser reincidente; composição familiar com pai, mãe e irmãos (comp_f_p_m_i), chance de 6,2 vezes; composição familiar sozinho (comp_soz), chance de 3,7 vezes; possui imóvel, chance de 2,5 vezes.

Quanto ao item "sem instrução escolar", segundo Fajnzylber (2000), menores níveis de educação e, por consequência, menores salários estão associados com as maiores taxas de crime. Araujo Jr. e Fajnzylber (2000) também confirmam que baixos índices de escolaridade dos criminosos demonstram como o menor custo de oportunidade a eles associados tem influenciado a tomada de decisão de o indivíduo migrar para a atividade ilegal.

Quanto à composição familiar nota-se uma aparente contradição, com ocorrência de uma

$$
\begin{aligned}
& P=\frac{1}{-\left(-1,200 \text { praticante+2,166Esc_sem_inst }+1,808 c o m p \_f \_p \_m \_i+1,307 c o m p \_s o z+0,78 u s a v a \_d r o g+1,817\right. \text { roubo_157+ }} \\
& 1+e^{4,191 \text { furto_155+2,062traf_drog_12+1,268uso_arma_fog+0,927imoveis }+1,568 \text { alto_suc_7-1,48ret_econ_o-2, } 471 \text { cons tan } t)}
\end{aligned}
$$


Tabela 1 - Variáveis do modelo Logit que compõem a equação "reincidência" após o $13^{\circ}$ passo do método stepwise forward dados primários obtidos no Complexo de Penitenciárias de Piraquara (Paraná), com criminosos econômicos

\begin{tabular}{lcccccc}
\hline Variáveis Independentes & $\boldsymbol{B}$ & S.E. & $\begin{array}{c}\text { Teste } \\
\text { Wald }\end{array}$ & df & Sig. & Exp(B) \\
\hline praticante & $-1,200$ &, 375 & 10,231 & 1 &, 001 &, 301 \\
esc_sem_inst & 2,166 & 1,017 & 4,540 & 1 &, 033 & 8,727 \\
comp_f_p_m_i & 1,808 &, 621 & 8,486 & 1 &, 004 & 6,099 \\
comp_soz & 1,307 &, 497 & 6,925 & 1 &, 008 & 3,696 \\
usava_drog &, 780 &, 341 & 5,248 & 1 &, 022 & 2,182 \\
roubo_157 & 1,817 &, 462 & 15,490 & 1 &, 000 & 6,152 \\
furto_155 & 4,191 &, 912 & 21,116 & 1 &, 000 & 66,082 \\
traf_drog_12 & 2,062 &, 585 & 12,413 & 1 &, 000 & 7,862 \\
uso_arma_fog & 1,268 &, 428 & 8,785 & 1 &, 003 & 3,553 \\
Imóvel &, 927 &, 369 & 6,308 & 1 &, 012 & 2,528 \\
alto_suc_7 & 1,568 &, 634 & 6,115 & 1 &, 013 & 4,798 \\
ret_econ_0 & $-1,487$ &, 472 & 9,906 & 1 &, 002 &, 226 \\
Constant & $-2,471$ &, 625 & 15,636 & 1 &, 000 &, 084 \\
\hline
\end{tabular}

Fonte: Dados da pesquisa

composição familiar dita ideal (pai, mãe e irmãos) e umperfil solitário. Nesse processo, "o comportamento individual é, de certo modo, resultado das condições criadas pelas próprias famílias, pelo indivíduo e pela sociedade em que vive" (BRENNER, 2009, p. 63). Constatou-se, nesta pesquisa, que, em $38 \%$ dos casos, existiam antecedentes criminais no seio familiar. Deriva-se, então, uma ressalva já atestada por Borilli (2005, p.112-113): “a família, enquanto um dos alicerces do bom andamento da sociedade, não está sendo uma aliada no combate ao crime e/ou repasse dos bons costumes aos seus membros". Para Wilson e Herrnstein (1986), a família pode ser capaz de minimizar ou maximizar qualquer tendência natural da criança, moldando seus valores.

O item imóvel (chance de 2,5 vezes) denota uma particularidade de alguns agentes criminosos que é retratada com pouca frequência. Schaefer (2000) expõe que causas individuais, consideradas de natureza psíquica, como cobiça, ambição, ganho fácil, entre outras, estão cada vez mais atraindo pessoas para as atividades ilegais. As pessoas atuam no meio criminal com a pretensão de montar um patrimônio melhor para si e sua família, mesmo que para isto esteja implícito o princípio hedonístico do máximo ganho com o mínimo de esforço.

Como variáveis explicativas que mensuram a importância da religiosidade e de hábitos e gostos com significância estatística, destacaram-se: prati- cante de uma religião (praticante); e uso de drogas (usava_drog). Considerando a prática religiosa, em função do $B$ ser negativo, se um agente criminoso tem esta característica, também considerada trava moral, sua chance de reincidência é menor que $1\left(e^{-1,200}=0,301\right)$, isto é, prática religiosa positiva, prática reincidente criminal menor. Shikida et al. (2005) atestaram em estudo empírico que, além dos incentivos tradicionais, travas morais podem alterar a ação de criminosos; desse modo, aqueles que praticam alguma religião poderiam ter custos maiores que benefícios em apresentar um comportamento criminoso. Já para quem faz uso de drogas (chance de 2,2 vezes) cabe destacar que "uma proporção importante dos crimes é realizada sob a influência de álcool, heroína, maconha etc." (BRENNER, 2009, p. 83). À guisa de Cooter e Ulen (2010), pode-se dizer que esta reincidência é comum no crime econômico por conta de três fatores motivacionais: $1^{\circ}$ ) alguns dependentes precisam cometer crimes para gerar renda, visando seu próprio consumo; $2^{\circ}$ ) as drogas podem fazer que os criminosos cometam mais ilícitos, na medida em que o seu uso provoca a redução da inibição, bem como a diminuição das regras morais restritivas e do valor das normas; $3^{\circ}$ ) com o retorno financeiro atrativo do tráfico de drogas, mais pessoas migram para esta atividade não pensando em atuar aí somente uma única vez. Neste último fator cabe incorporar à discussão a variável tráfico de 
drogas (traf drog 12), na qual a chance de ser reincidente é de 7,9 vezes. Para Fernandez e Maldonado (1999), para a surpresa de muitos estudiosos e especialistas, o tráfico de drogas passou a ser considerado um grande negócio mundial e a expansão do mercado de drogas vem afetando positivamente o crime (MARIANO, 2010).

Para a variável "uso de arma de fogo" (uso arma_fog), a chance de reincidência é de 3,6 vezes. Embora a jurisprudência majoritária reconheça o aumento da punição em razão da tipificação do uso de arma de fogo no crime (SANCHES, 2008), o que está implícito neste estudo é o fato de a arma propiciar não só um processo intimidativo mais violento, mas também uma perspectiva maior de benefício ante o custo dessa violência. Pois, se o criminoso percebe que suas vítimas estão armadas, há menor probabilidade de ele cometer um crime (COOTER e ULEN, 2010).

Por último, mas não menos importante, tem-se a variável que mensura o sucesso na atividade ilícita (alto_suc_7) e o baixo retorno econômico (ret_econ_0). Cabe esclarecer que o coeficiente alto_suc_7 advém de uma escala, de 0 a 9, que considera o sucesso da prática criminosa. Neste caso, a média foi 7 . Neste sentido, uma pessoa que tenha resultados satisfatórios numa atividade criminosa tem 4,8 vezes mais chance de ser reincidente. A variável "baixo retorno econômico" (ret_econ_0) corrobora esta análise na medida em que seu $B$ é negativo, ou seja, com retorno nulo na atividade ilegal a possibilidade de reincidência é menor que $1\left(e^{-1,487}=0,226\right)$, o que significa que se o crime não for rendoso, não haverá reincidência. Em suma, estas duas variáveis mostram que, se houver sucesso das atividades ilegais e o retorno financeiro esperado for elevado, as atividades criminais serão preferíveis às atividades legais. Jones (1977) e Schaefer (2000) expõem este fato em seus trabalhos.

Mediante as características pessoais, socioeconômicas, de herança familiar, fatores catalisadores, religiosos e de hábitos e gostos de qualquer um dos carcerários é possível calcular sua probabilidade de reincidência. As probabilidades de reincidência de cada indivíduo pesquisado é uma somatória de probabilidades de suas características pessoais. É preciso lembrar que foi dada a garantia de anonimato para os réus pesquisados, portanto, não serão analisados seus reais perfis individualmente. Apenas serão expostos os valores das probabilidades de reincidência, apresentados no Gráfico 1, não caracterizando cada preso especificamente.

As observações correspondentes aos números de 1 a 90 representam os presos reincidentes, sendo o restante os não reincidentes. Fica evidente que os reincidentes têm maior probabilidade de chances de

Gráfico 1 - Probabilidades de reincidência dos entrevistados

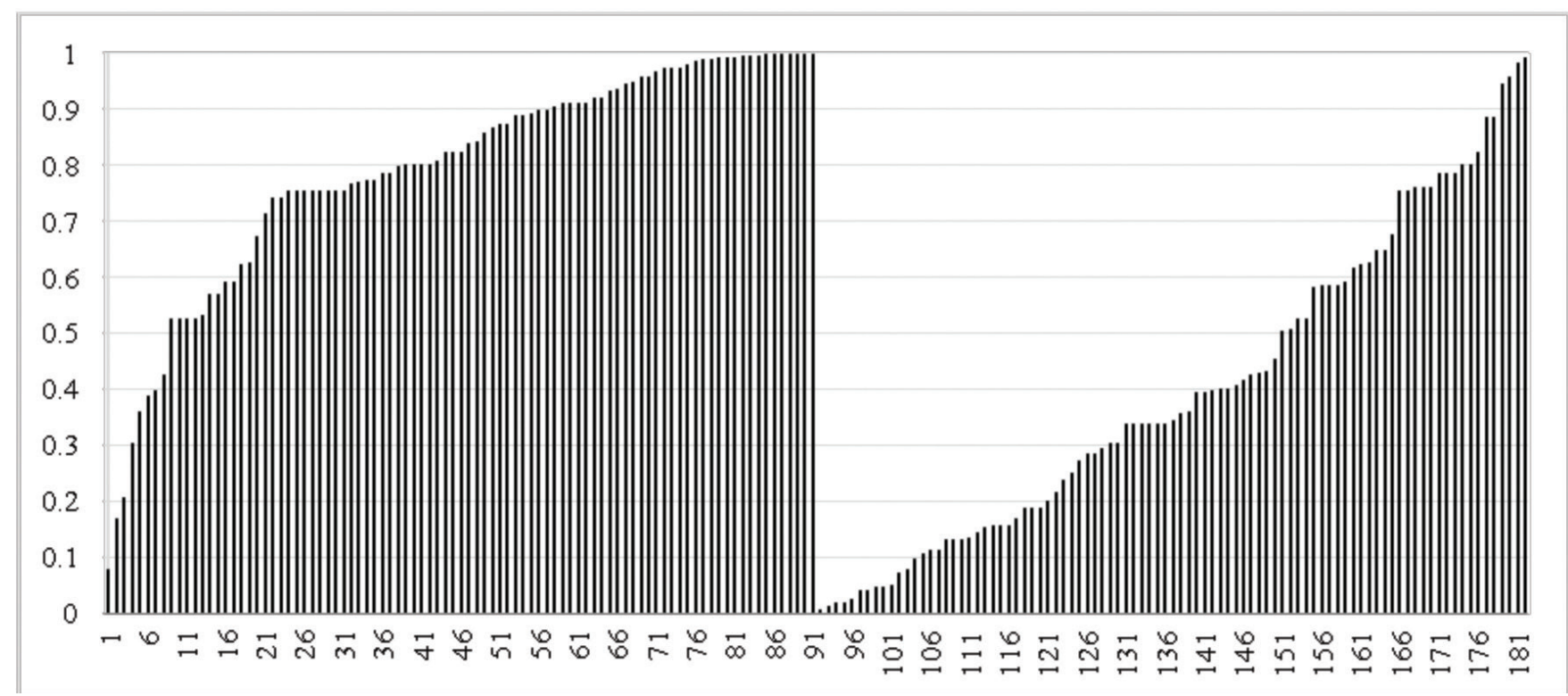

Fonte: Dados da pesquisa 
reincidência do que os que não o são. Ressalta-se que a média da probabilidade de reincidência de todos os entrevistados foi de $59,33 \%$, enquanto para os reincidentes e não reincidentes a média foi de $78,90 \% \mathrm{e}$ $39,76 \%$, respectivamente. Ou seja, mesmo entre os não reincidentes ainda é alta a probabilidade de reincidência penal no Brasil.

\section{CONSIDERAÇÕES FINAIS}

Este artigo teve como objetivo analisar os determinantes da reincidência penal no Brasil, por meio de um estudo empírico no Complexo de Penitenciárias de Piraquara (Paraná), a partir de dados primários obtidos através da aplicação de questionários/entrevistas a réus já julgados e condenados por crimes econômicos. Para estimar os determinantes da reincidência penal foi analisada a correlação, em termos probabilísticos, de variáveis pessoais, socioeconômicas, de herança familiar, fatores catalisadores, religiosos e de hábitos e gostos, com uma variável dependente binária construída para capturar o que se define como reincidência penal. Neste sentido, o modelo utilizado foi o Logit.

Entre as variáveis com significância estatística, o método utilizado permitiu selecionar as seguintes: praticante de uma religião; sem instrução escolar; composição familiar com pai, mãe e irmãos; composição familiar sozinho; uso de drogas; tipo de crime roubo; tipo de crime furto; tipo de crime tráfico de drogas; uso de arma de fogo; possui imóvel; alto sucesso na atividade ilícita; e baixo retorno econômico.

Entre as variáveis mais expressivas resultantes do modelo aplicado, o destaque ímpar foi para o furto, que apresentou para o agente praticante deste tipo de delito 66 vezes mais chance de ser reincidente. As outras variáveis ficaram abaixo de 10 vezes mais chance de reincidência, assim ordenadas: sem instrução escolar (8,7 vezes); tipo de crime tráfico de drogas (7,9 vezes); tipo de crime roubo ( 6,2 vezes); composição familiar com pai, mãe e irmãos $(6,1$ vezes); alto sucesso na atividade ilícita (4,8 vezes); composição familiar sozinho ( 3,7 vezes); uso de arma de fogo (3,6 vezes); possui imóvel (2,5 vezes) e uso de drogas (2,2 vezes).

Como era de se esperar, verificou-se que a trava moral, ser praticante de uma religião, contribui para tolher a criminalidade ( $B$ negativo), haja vista a chance de reincidência penal ter sido menor que 1 . Nesta linha de coeficiente $B$ negativo, o baixo retorno econômico também evidenciou uma chance de reincidência menor que 1 .

As outras travas morais, família e escola, consideradas importantes no tolhimento da criminalidade, podem ser constatadas na presente pesquisa pelo não aparecimento de ocorrências com significância estatística para os níveis de educação mais elevados. No caso da família, houve uma dicotomia, pois as chances de reincidência penal aumentam quando uma pessoa vive isolada na sociedade, relegada do seio familiar. Contudo, mesmo se a família for composta quantitativamente, mas não repassar boa educação, moral e ética para seus membros, o efeito é contraproducente em termos de bons costumes, e a reincidência criminal será estimulada.

O contexto geral do resultado das variáveis supracitadas permite inferir que há racionalidade do criminoso econômico reincidente, que postula uma alocação ótima do seu tempo numa atividade ilícita considerada mais propensa à repetição, fazendo uso de arma de fogo em alguns casos. Logo, o que este agente procura é maximizar a função relativa à utilidade esperada que depende, fundamentalmente, do retorno pecuniário de sua ação, não reincidindo caso sua atividade apresente expectativa de baixo lucro. Assim sendo, os ganhos esperados no setor ilegal precisam superar os custos de migração para esse setor para que o indivíduo possa reincidir no crime. Isto, evidentemente, pensando em acumulação material retratada, neste caso, pela variável "bem imóvel".

Nesta pesquisa, para os criminosos reincidentes, o crime compensa mais do que o trabalho lícito, com tendência para o furto, tráfico de drogas e roubo, nesta sequência. Por conta de fragilidades morais em suas personalidades, os reincidentes penais valorizam em demasia os benefícios econômicos do crime e subestimam seus custos, sejam estes morais ou não morais.

Como política pública para tolher a reincidência penal, a solução ideal deve ser a de que o resultado do crime não deve ser compensador. Logo, a sociedade organizada, e mesmo a não organizada, deve se unir para procurar diminuir ou mesmo tornar nulo o retorno pecuniário do agente criminoso e/ou aumentar o risco de sua atividade ilegal. Contudo, melhorar 
a polícia, melhorar as leis e a justiça, melhorar os aparatos de segurança, fazer crescer e desenvolver a economia são condições necessárias, mas não suficientes no combate à criminalidade, se não houver investimentos constantes no tripé basilar da formação do ser humano: família, escola e religião. Reconstruir a perspectiva da família como núcleo social primário do cidadão é condição sine qua non.

A Escola é outra importante base de formação educacional, moral e ética de um cidadão. Quem não investe em educação não sabe o custo da ignorância, ou quer a ignorância prevalecendo; só que este custo também se mede em termos de reincidência penal. A religião que, com suas crenças sobre a natureza e finalidade da vida, pode muito bem moldar o comportamento humano para o que é justo e perfeito, teve sua relevância confirmada por seu resultado estatístico em termos de chances de reincidência menor que 1. Recuperar a base familiar e escolar do cidadão, pari passu ao fortalecimento das instituições polícia, justiça, Estado etc., é o insight deste corolário em termos de políticas públicas para, de fato, procurar minimizar não só a reincidência penal como a própria causa de migração para a atividade econômica ilícita.

\section{REFERÊNCIAS}

ARAUJO JR., A. F. de. Raízes econômicas da criminalidade violenta no Brasil: um estudo usando micro dados e pseudopainel - 1981/1996. Revista de Economia e Administração, v. 1, n. 3, p. 1-34, jul/set. 2002.

ARAUJO JR., A. F. de; FAZNZYLBER, P. Crime e economia: um estudo das microrregiões mineiras. Revista Econômica do Nordeste, v. 31, número especial, p. 630659, nov. 2000.

BALBINOTTO NETO, G. A teoria econômica do crime. Revista Leader, edição n. 35, fev./2003. Disponível em: $<$ http://www.iee.com.br/leader/edicao_35/index.asp $>$. Acesso em: 20 ago. 2011.

BARREIROS, Y. S. de A. A reincidência no sistema jurídico brasileiro. 2007. Disponível em: <http://br.monografias. com/trabalhos909/a-reincidencia-sistema/a-reincidenciasistema.shtml >. Acesso em: 16 ago. 2011.

BARTH, N. L. Inadimplência: construção de modelos de previsão. São Paulo: Nobel, 2004.

BECKER, G. S. Crime and punishment: an economic approach. Journal of political economy, v. 76, n. 01, p. 169217, 1968.
BECKER, H. S. Estudo de praticantes de crimes de delitos. In: Métodos de pesquisa em ciências sociais. 4. ed. São Paulo: HUCITEC, 1999, p.153-178.

BEMFICA, F. V. Da teoria do crime. São Paulo: Saraiva, 1990.

BENTHAM, J. ([1788] 1843). Principles of penal law. Reprinted in The Works of Jeremy Bentham (John Hill Burton ed., 1843).

BORILLI, S. P. Análise das circunstâncias econômicas da prática criminosa no Estado do Paraná. Toledo, UNIOESTE, 2005. (Dissertação de Mestrado em Desenvolvimento Regional e Agronegócio).

BRENNER, G. Entendendo o comportamento criminoso - a educação, ensino de valores morais e a necessidade de coibir o comportamento criminoso: uma contribuição da teoria econômica e um recado para nossas autoridades. Porto Alegre: Age, 2009.

CERQUEIRA， D.; LOBÃO, W. Determinantes da criminalidade: uma resenha dos modelos teóricos e resultados empíricos. Texto para Discussão. IPEA: Rio de Janeiro, junho de 2003, 31 p.

CÓDIGO PENAL. Decreto-Lei no 2.848 , de 7 de dezembro de 1940. Disponível em: <http://www.planalto.gov.br/ ccivil_03/decreto-lei/Del2848compilado.htm>. Acesso em: 21 ago. 2011.

COOTER, R.; ULEN, T. Direito e economia. $5^{\text {a }}$ ed. Porto Alegre: Editora Bookman, 2010.

DEPARTAMENTO PENITENCIÁRIO NACIONAL. Execução penal. InfoPen - Estatística 2010 e 2011. Disponível em: <http://portal.mj.gov.br/data/Pages/ MJD574E9CEITEMIDC37B2AE94C6840068B1624D284 07509CPTBRNN.HTM $>$ e $<$ http://portal.mj.gov.br/main. asp?View $=\%$ 7BD574E9CE-3C7D-437A-A5B6-22166AD $2 \mathrm{E} 896 \% 7 \mathrm{D} \& \mathrm{Team}=\&$ params $=$ itemID $=\%$ 7BC37B2AE94C68-4006-8B16-24D28407509C\%7D;\&UIPartUID $=\%$ 7B2868BA3C-1C72-4347-BE11-A26F70F4CB26\%7D>. Acesso em: 20 out. 2012.

EIDE, E. Economics of criminal behavior. 1999. Disponível em $<$ http://encyclo.findlaw.com/8100book.pdf $>$. Acesso em: 17 ago. 2011.

FAJNZYLBER, P. Determinantes econômicos da criminalidade: notas para uma discussão. Rio de Janeiro: IPEA, 2000.

FERNANDEZ, J. C.; MALDONADO, G. E. C. A economia do narcotráfico: uma abordagem a partir da experiência boliviana. Nova Economia. Belo Horizonte: v. 9, n. 02, p. 137-173, dez. 1999.

GIL, A. C. Técnicas de pesquisa em economia e elaboração de monografias. São Paulo: Atlas, 2000. 
HILL, C. R.; GRIFFITHS, W. E.; JUDGE G. G. Econometria. 2. ed. São Paulo: Saraiva, 2006.

HOSMER, D. W., LEMESHOW, S. Applied logistic regression. 2. ed. USA: Wiley Publication, 2000.

JONES, R. A oferta nas economias de mercado. Rio de Janeiro: ZAHAR, 1977.

MACHADO, L. M. Breve estudo sobre a reincidência penal. 2006. Disponível em: $<$ http://sisnet.aduaneiras.com. $\mathrm{br} / \mathrm{lex} /$ doutrinas/arquivos/breve.pdf $>$. Acesso em: 26 ago. 2011.

MARIANO, R. S. Fatores socioeconômicos da criminalidade no Estado de São Paulo: um enfoque da economia do crime. São Paulo, PUC-SP, 2010. (Dissertação de Mestrado em Economia).

PAULA, Á. N. de. Efeitos da reincidência de acordo com a doutrina. Jus Navigandi, Teresina, ano 8, n. 65, 1 mai. 2003. Disponível em: <http://jus.uol.com.br/revista/texto/4009>. Acesso em: 16 ago. 2011.

PIERANGELLI, J. H. Códigos penais do Brasil: evolução histórica. Bauru (SP): Jalovi, 1980.
SANCHES, H. G. O uso de arma de fogo no crime de roubo sempre ensejará a causa especial de aumento de pena prevista no art. $157, \S 2^{\circ}$, inciso I, do Código Penal? Jus Navigandi, Teresina, ano 13, n. 65, 11 jul. 2008. Disponível em: <http:// jus.uol.com.br/revista/texto/11479>. Acesso em: 16 ago. 2011.

SCHAEFER, G. J. Economia do crime: elementos teóricos e evidências empíricas. Toledo, UNIOESTE, 2000. (Monografia de Ciências Econômicas).

SHIKIDA, C. D.; ARAUJO JR., A. F. de; SHIKIDA, P. F. A. A moral importa? Revista de Economia e Administração, São Paulo (SP), v. 4, n. 4, p. 415-426, out./dez. 2005.

SHIKIDA, P. F. A. Considerações sobre a economia do crime no Brasil: um sumário de 10 anos de pesquisa. Revista de Análise Econômica do Direito, v.1, n. 2, jul./dez. 2010, p. 324-344,.

WILSON, J. Q.; HERRNSTEIN, R. J. Crime and human nature. New York: Simon \& Schuster, 1986.

Recebido em novembro de 2013. Aceito em fevereiro de 2014. 